\title{
Intracranial vessel wall MRI: a review of current indications and future applications
}

\author{
Adam de Havenon ${ }^{1 *}$, Lee Chung ${ }^{1}$, Min Park ${ }^{2}$ and Mahmud Mossa-Basha ${ }^{3}$
}

\begin{abstract}
Background: Intracranial vessel wall MRI (IVWM) is a new diagnostic imaging approach with the goal of evaluating intracranial vascular pathology by directly visualizing arterial vessel wall abnormalities with MR sequences, preferably at 3 Tesla field strength, that suppress blood and have excellent spatial resolution.

Body: The differentiation of intracranial vascular pathology has historically relied on luminal imaging techniques that depict the alteration of flow created by atherosclerotic stenosis or vasospasm. With IMWM, it is possible to identify distinct radiologic findings of the pathology within the intracranial vessel wall itself, ranging from arterial dissection to vasculitis. Futhermore, IVWM imaging characteristics, such as post-contrast enhancement, can elucidate the temporal relationship between imaging findings and clinical pathology; and may predict future behavior of unruptured aneurysms or atherosclerotic plaques.
\end{abstract}

Conclusion: We present a review of the basic IVWM imaging techniques and the relevant published literature on IVWM, with a focus on evidence-based diagnostic indications for IVWM and discussion of the strengths and weaknesses of each indication. Finally, we discuss how IVWM can be used to differentiate between intracranial pathology and future directions for IVWM research.

Keywords: Vessel wall MRI, Black blood MRI, High-resolution MRI, Intracranial atherosclerosis, Intracranial aneurysm, CNS vasculitis

\section{Background}

Intracranial vessel wall MRI (IVWM) is a term for different MRI sequences that share the common goal of achieving sufficient resolution and contrast such that the vessel wall and overlying tissue, such as atherosclerotic plaque, can be accurately assessed; and to differentiate between intracranial vascular pathologies that were previously evaluated with luminal imaging. IVWM, as compared to extracranial vessel wall imaging, is more challenging due to the small caliber and tortuous course of the intracranial arteries. For example, the middle cerebral artery diameter can range from 3 to $5 \mathrm{~mm}$, with a vessel wall thickness from 0.5 to $0.7 \mathrm{~mm}$ [1]. While some protocols have used $1.5 \mathrm{~T}$ scanners, $3 \mathrm{~T}$ is preferable because of the need for very high resolution and small voxels to accurately depict the normal arterial wall and differentiate between pathological states.

\footnotetext{
* Correspondence: adam.dehavenon@hsc.utah.edu

'Department of Neurology, University of Utah, Salt Lake City, USA

Full list of author information is available at the end of the article
}

In addition, with decreased in-plane and through-plane resolution, there is increased likelihood of volume averaging and wall blurring [2]. Both 2D and 3D IVWM techniques can be employed depending on the scanning environment and institutional experience [2-13] (Table 1). An important consideration for intracranial vessel wall imaging is blood and cerebrospinal fluid (CSF) suppression for better outer wall boundary evaluation. For 2D vessel wall imaging techniques, spin echo techniques will generate dark blood and are frequently used, but a major limitation is that with slow or in-plane flow, blood suppression will be lost. Multiplanar 2D techniques permit imaging in a plane perpendicular to the axis of the interrogated artery, allowing more complete visualization of the lesion morphology, assessment of its effects on the lumen, minimization of volume averaging effects and accurate estimation of wall thickness. Vessel obliquity, slice thickness and in-plane resolution are all factors that affect wall measurements and the sharpness of the vessel wall borders [14]. Cardiac gating may be performed for 2D IVWM, but its benefit is debatable [2]. 
Table 1 Common IWWM pulse sequences with advantages/disadvantages

\begin{tabular}{|c|c|c|}
\hline Pulse sequence & Advantages & Disadvantages \\
\hline $\begin{array}{l}\text { 3D time of flight (TOF) MRA } \\
\text { (non-contrast) }\end{array}$ & $\begin{array}{l}\text { Flow-related enhancement allows identification of } \\
\text { luminal abnormality or aneurysm for measurement } \\
\text { and placement of IVWM sequences }\end{array}$ & $\begin{array}{l}\text { Luminal imaging alone may not identify non-stenotic } \\
\text { vessel abnormalities (outwardly remodeling plaque, } \\
\text { non-stenotic dissection, etc.). TOF overestimates stenosis } \\
\text { secondary to flow dephasing artifact. It also shows diminished } \\
\text { flow in slow flow or in-plane flow states. These are overcome } \\
\text { with contrast-enhanced TOF MRA }\end{array}$ \\
\hline $\begin{array}{l}\text { 2D turbo spin echo (TSE) or fast } \\
\text { spin echo (FSE) }\end{array}$ & $\begin{array}{l}\text { Wide availability, good in-plane resolution, flexible } \\
\text { tissue contrast, reduced sensitivity to magnetic field } \\
\text { inhomogeneities, high SNR, can image focused area } \\
\text { of interest in rapid acquisition to limit motion artifact }\end{array}$ & $\begin{array}{l}\text { Low spatial resolution in the slice-select direction leading } \\
\text { to partial volume effect that can hide subtle findings, poor } \\
\text { reproducibility, inability to create multiplanar reformats. } \\
\text { Requires multi-planar scanning which is time consuming }\end{array}$ \\
\hline $\begin{array}{l}\text { 3D variable refocusing flip angle } \\
\text { (VRFA) sequences (VISTA, Philips; } \\
\text { SPACE, Siemens; CUBE, GE) }\end{array}$ & $\begin{array}{l}\text { High SNR with excellent spatial resolution, superior } \\
\text { anatomic coverage, T1/T2/PD weightings available, } \\
\text { ability to reformat into multiplanar images that } \\
\text { allow viewing of vessel wall, plaque, or aneurysm } \\
\text { from any aspect. Shorter overall scan time }\end{array}$ & $\begin{array}{l}\text { Requires research preparation prepulse sequence for blood } \\
\text { suppression, longer acquisition times for slab can result } \\
\text { in motion artifact, more susceptible to magnetic field } \\
\text { inhomogeneities }\end{array}$ \\
\hline $\begin{array}{l}\text { Blood suppression prepulse: } \\
\text { • Double inversion-recovery }\end{array}$ & $\begin{array}{l}\text { Available as a commercial pulse, negligible effect } \\
\text { on image contrast weighting }\end{array}$ & $\begin{array}{l}\text { Blood-suppression difficult after contrast administration, } \\
\text { does not work with 3D techniques }\end{array}$ \\
\hline $\begin{array}{l}\text { Blood suppression prepulse: } \\
\text { • Motion-sensitive driven } \\
\text { equilibrium (MSDE) }\end{array}$ & $\begin{array}{l}\text { 3D blood suppression technique, robust to large } \\
\text { slab size acquisition, in-flow/outflow independent }\end{array}$ & $\begin{array}{l}\text { Can lead to loss of signal with } T 2 \text { weighting, inability to } \\
\text { implement } 180^{\circ} \text { pulse due to high specific absorption } \\
\text { rate, B1 inhomogeneity }\end{array}$ \\
\hline $\begin{array}{l}\text { Blood suppression prepulse: } \\
\text { • Delay alternating with nutation } \\
\text { for tailored excitation (DANTE) }\end{array}$ & $\begin{array}{l}\text { Best blood suppression, robust to large slab size } \\
\text { acquisition, in-flow/outflow independent, no loss } \\
\text { of T2 signal, performs well at } 7 T \text {, available on } \\
\text { research sequences from most vendors }\end{array}$ & $\begin{array}{l}\text { Longer imaging time than MSDE may create artifact from } \\
\text { vessel wall motion }\end{array}$ \\
\hline $\begin{array}{l}\text { Gradient-echo 3D T1-weighted } \\
\text { without blood suppression } \\
\text { (MP-RAGE, FLASH) }\end{array}$ & $\begin{array}{l}\text { Can identify intraplaque hemorrhage in atherosclerosis, } \\
\text { intramural hematoma in dissection, and aneurysmal } \\
\text { wall hematoma }\end{array}$ & $\begin{array}{l}\text { Lack of blood suppression can hide pathologic findings, } \\
\text { unclear significance of intracranial intraplaque hemorrhage. } \\
\text { MP-RAGE is preferred sequence }\end{array}$ \\
\hline
\end{tabular}

3D acquisitions allow for improved through-plane resolution and permit multi-planar reformations with isotropic acquisitions. 3D variable refocusing flip angle (VRFA) sequences (VISTA, Philips Healthcare, Best, the Netherlands; SPACE, Siemens Healthcare, Erlangen, Germany; CUBE, GE Healthcare, Milwaukee, WI, USA) have been the most extensively studied $3 \mathrm{D}$ techniques to date, as these sequences provide excellent image quality, coverage and blood flow suppression in a shorter scan time $[3,4,15,16]$. VRFA techniques have been used with $\mathrm{T} 1$ and proton density (PD) weightings, both before and after gadolinium contrast administration, as the pattern and degree of contrast enhancement can be helpful in differentiating and characterizing vasculopathies $[2,5]$. High-resolution 3D T2-weighted imaging has also shown promise for helping further differentiate intracranial vessel wall pathology [17].

The delay alternating with nutation for tailored excitation (DANTE) pulse train, which is a series of low flip angle nonselective pulses interleaved with gradient pulses with short repetition times, results in optimized blood and CSF suppression without effects on tissue contrast [10]. DANTE allows for improved vessel wall assessment with 3D VRFA techniques while also minimizing artifacts from turbulent or slow flow. In addition to VRFA sequences, another 3D technique that successfully suppresses blood flow is motion sensitized driven equilibrium (MSDE), which employs flow-sensitive dephasing gradients to suppress flow [18]. However, MSDE can result in T2 signal decay and loss of signal.

IVWM protocols can be performed in a time efficient manner. A 3D PD-weighted VRFA sequence $\left(0.4-0.5 \mathrm{~mm}^{3}\right.$ isotropic voxels) with coverage of the major intracranial arteries can be performed on a $3 \mathrm{~T}$ system in 7 to $11 \mathrm{~min}$ [2]. Thus a full protocol, including TOF MRA for localization and PD-weighted VRFA, pre and post contrast, can be performed in under $30 \mathrm{~min}$. As MRI scanners improve in efficiency, field strength, coil element technology and compressed sensing techniques become more efficient, sequences will further shorten with improved coverage [19]. Currently, the majority of research has been conducted using a 12- or 16-channel coil, although data suggests that a 32-channel coil improves the ability to detect pathology in the more peripheral vessels, and may become more prevalent in the future [20].

\section{Intracranial atherosclerosis (Fig. 1)}

Compared to time-of-flight (TOF) MRA, which measures degree of stenosis, IVWM is able to characterize multiple imaging features of intracranial plaque [21] and has been more sensitive for the identification of symptomatic atherosclerotic lesions [5]. IVWM is also helpful to identify the morphology of intracranial vessels at [22] or distal [23] to an arterial occlusion, lesions 


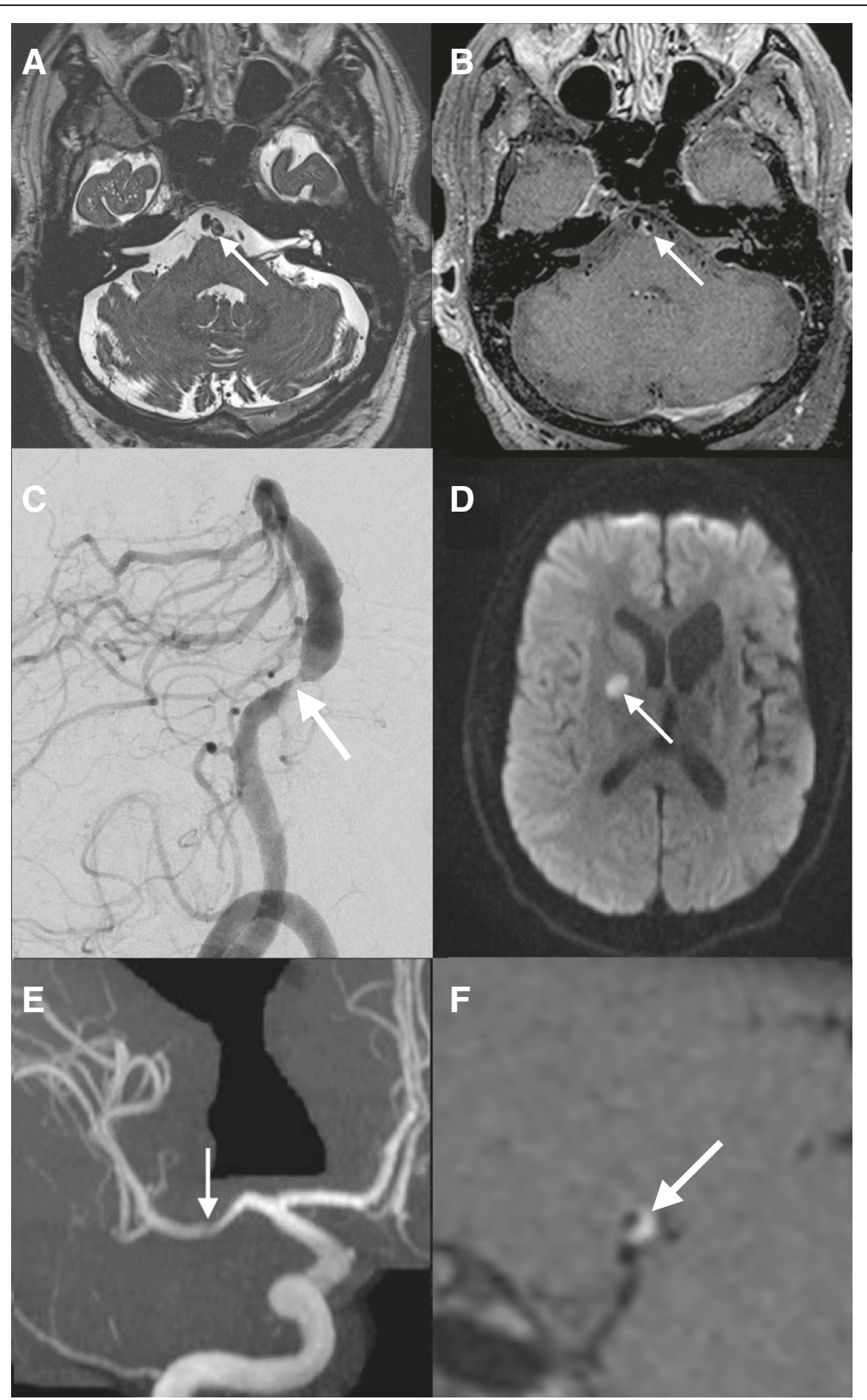

Fig. 1 All images were created with a 3T MRI and 16-channel head coil. a 3D axial T2-weighted image of atherosclerotic plaque (white arrow) at the vertebrobasilar junction in a patient who presented with a transient ischemic attack. Note the juxtaluminal T2 hyperintensity, depicting the fibrous cap. b 3D axial T1-weighted image post-contrast showing eccentric vessel wall enhancement, consistent with a recently symptomatic atherosclerotic plaque, and outward remodeling of the plaque. $\mathbf{c}$ Digital subtraction angiogram of the same patient in (a) and (b), showing a lateral view of the atherosclerotic stenosis at the vertebrobasilar junction. $\mathbf{d}$ Diffusion-weighted image and apparent diffusion coefficient axial images of a second patient who presented with left-sided weakness and was found to have an acute ischemic stroke in the right internal capsule (white arrows). e TOF MRA shows minimal stenosis in the right M1 segment (white arrow) of the middle cerebral artery, at the origin of the lenticulostriate perforators that supplied the distribution of the ischemic stroke. f Sagittal reconstruction of the same right M1 segment again demonstrates eccentric wall enhancement, consistent with recently symptomatic atherosclerotic plaque, and outward remodeling at the site of the enhancement

that MRA and CTA do not visualize well. IVWM studies of intracranial stenosis suggest that IVWM is more accurate than MRA at measuring degree of luminal stenosis, [24, 25] and can identify symptomatic non-flow- limiting intracranial lesions in ischemic stroke that would normally be missed by standard luminal imaging [26].

Compared to asymptomatic MCA atherosclerotic plaques, recently symptomatic plaques are larger and 
irregularly surfaced with increased ratio of plaque thickening to patent vessel lumen [27-32]. Among MCA plaques with associated deep penetrating artery infarctions, plaque tended to be more superior and less ventral $[28,31]$. Symptomatic MCA plaques typically have positive remodeling, characterized by outward remodeling of the stenotic vessel area [26, 28, 29, 33], an association first demonstrated in coronary arterial atherosclerosis $[34,35]$. Several studies of pontine ischemic stroke patients have shown that IVWM is more sensitive than TOF MRA to the presence of symptomatic basilar artery (BA) plaque, even in pontine lacunar infarctions, [36] and more predictive of progressive motor deficit during hospitalization [37].

Carotid artery plaque hemorrhage is considered a risk factor of ischemic stroke [38-40]. Histopathological studies of carotid plaque have shown that intraplaque high-intensity signal on vessel wall imaging techniques correlate well with the presence of intraplaque hemorrhage (IPH) [41]. These same principles can be applied to intracranial plaques to both identify the etiology of medium-to-large-vessel stroke and potentially to stratify future risk of ischemic stroke due to intracranial stenosis. For example, T1, T2 and PD weighted IVWM hyperintensity was found to be more common among symptomatic $(57.1 \%)$ vs. asymptomatic (22\%) MCA plaques [42], a finding which has been replicated in several studies $[43,44]$. In the posterior circulation, a study of 73 patients with $>50 \%$ BA stenosis found that IPH, detected on the nonblood suppressed 3D magnetization-prepared rapid gradient-echo (MP-RAGE) sequence, was associated with a 1.64 relative risk of a focal stroke event on DWI $(p<0.01)$, with a sensitivity of $80.0 \%$ and specificity of $46.5 \%$ [ 45$]$.

Compared to MRA, IVWM permits the evaluation of wall enhancement in intracranial arterial atherosclerosis and the potential identification of sources of acute stroke [12]. This was first demonstrated among 13 ischemic stroke patients who received a 3T IVWM protocol that was compared to CTA, MRA, or catheter angiogram. $12 / 13(92.3 \%)$ patients with symptomatic intracranial atherosclerosis had focal areas of eccentric wall enhancement in the relevant major branches of the circle of Willis supplying the area of infarct and 10/12 (83.3\%) had enhancement only in the vessel supplying the infarct [46]. Another study followed acute stroke patients with intracranial atherosclerotic stenosis with IVWM and found strong vessel wall enhancement in all patients imaged within 4 weeks of acute stroke and that the strength and presence of enhancement decreased in the subacute (4-12 weeks) and chronic (>12 weeks) phases [47]. A recent study performed 3T IVWM on 138 patients with symptomatic atherosclerotic plaque of varying degrees of stenosis (108/138 had plaque enhancement) and followed the patients for a median of 18 months [48] There were 39 stroke recurrences, of which 37/39 were in patients with enhancing plaques, creating a hazard ratio of 7.42 for recurrent stroke among the patients with enhancing plaque.

Given that interobserver reliability for plaque morphology, presence of intracranial IPH and enhancement pattern on contrasted IVWM is excellent [49, 17], it would appear that IVWM could reliably identify symptomatic atherosclerosis. However, it is important to consider that all IVWM findings are also seen in asymptomatic atherosclerosis [4, 33, 45], suggesting that IVWM findings such as plaque enhancement or IPH could be useful for identifying symptomatic atherosclerotic plaque, but only in combination given their individually moderate sensitivity and low specificity. Additional long-term prospective studies with serial radiographic and clinical follow-up, ideally with pathologic correlation, are needed to better understand the clinical significance of these techniques and how they may be combined to optimally characterize intracranial atherosclerosis and predict medical treatment failure, because intracranial atherosclerosis has an annual rate of recurrent stroke that is three times the average of other stroke etiologies (13-18 versus $5 \%$ ) and IVWM research suggests it may be even higher in the subgroup of patients with enhancing plaque $[48,50,51]$.

\section{Intracranial aneurysm (Fig. 2)}

IVWM has been used to identify ruptured intracranial aneurysms (IA). An early study showed that in 5 cases of subarachnoid hemorrhage, the culprit IA consistently demonstrated wall enhancement at the site of rupture [52]. Several of the IAs also demonstrated pre-contrast T1 shortening consistent with intramural hematoma. A larger study of 117 patients, with 61 ruptured and 83 unruptured IAs, used an MSDE 3D pre- and post-contrast protocol that detected "strong/faint enhancement" in 73.8/24.6\% of the ruptured IAs and only $4.8 / 13.3 \%$ of the unruptured IAs [53]. These results suggest that IA wall enhancement on 3D T1- or PD-weighted post-contrast IVWM could serve as a marker for aneurysm rupture in the 12$20 \%$ of subarachnoid hemorrhage patients found to have multiple IAs, although further investigation is necessary considering that early studies have indicated that unstable unruptured aneurysms may also show wall enhancement $[54,55]$.

Unruptured intracranial aneurysms (IAs) are a relatively common imaging finding, incidentally found in up to $2 \%$ of luminal imaging studies [56]. Given the historical difficulty in risk stratifying unruptured IAs, IVWM has been used to identify the underlying arterial wall inflammation that is hypothesized to be the driving force 


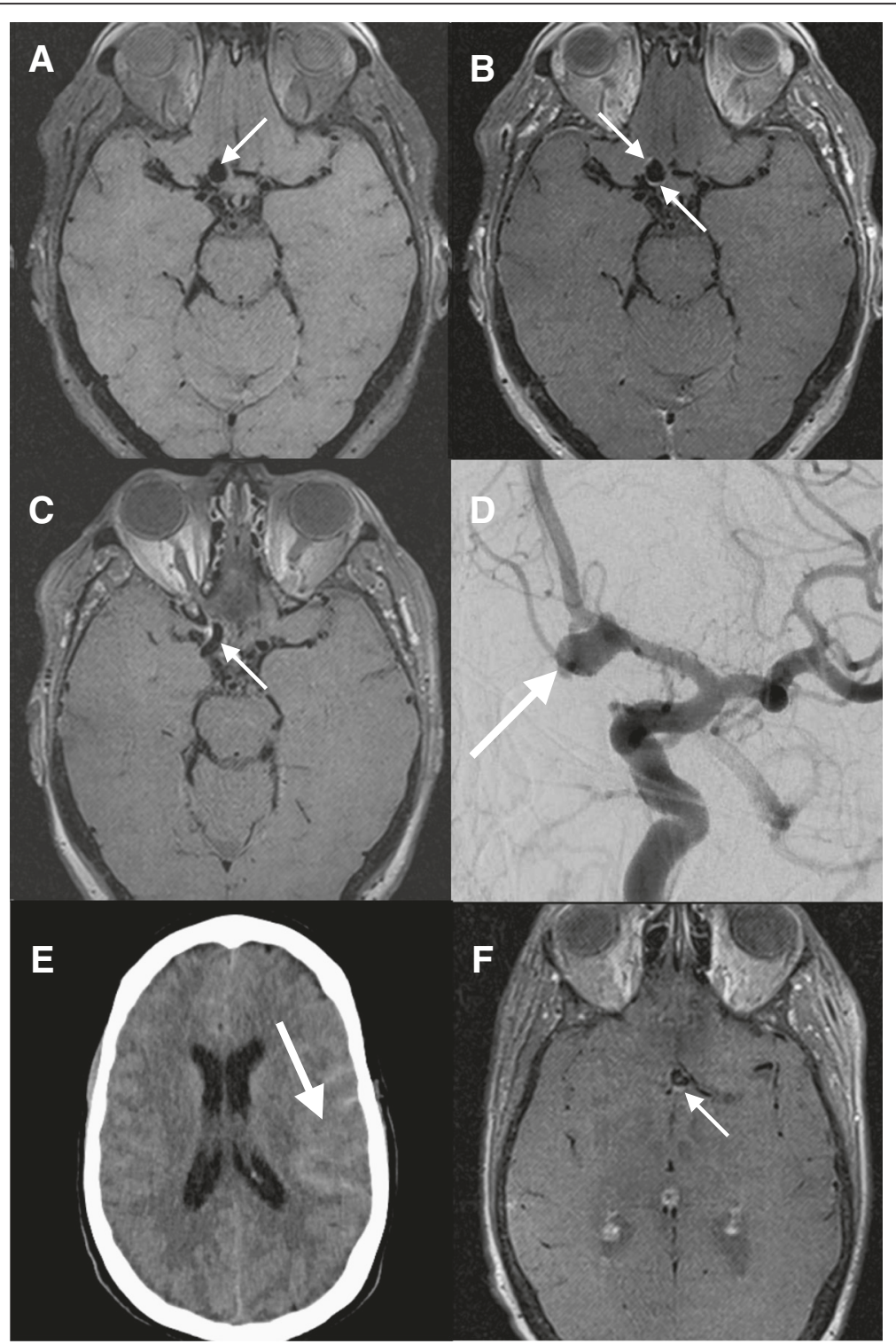

Fig. 2 a 3D axial T1-weighted image showing a large internal carotid artery unruptured aneurysm (white arrow). b 3D axial T1-weighted post-contrast image showing enhancement of the aneurysm wall, concerning for active inflammation and instability. c 3D axial T1-weighted post-contrast image after placement of a flow-diverting stent, which has not yet occluded the aneurysm, but has created a small area of enhancement remote from the aneurysm (white arrow), that has been reported after flow-diverting stent placement presumed to be related to local inflammation or thrombosis. d, e A second patient who presented with thunderclap headache and was found to have an anterior communicating artery aneurysm (d, white arrow, digital subtraction angiogram, lateral projection), which had ruptured and caused subarachnoid hemorrhage (e, white arrow, CT noncontrast, axial). f 3D axial T1-weighted post-contrast image showing enhancement of the aneurysm wall, consistent with recent rupture

of IA pathogenesis and, potentially, rupture [57]. The first IVWM study of unruptured IAs imaged 14 patients with saccular IAs using 2D sequences on a $1.5 \mathrm{~T}$ MRI and found that evaluating IA wall thickness and structure was easier on T1-weighted than T2-weighted sequences [58]. A study of 35 pre-surgical unruptured IAs predicted wall thickness using a combination of a 3D T1 sequence and a 3D steady-state free procession (SSFP) gradient echo sequence, to retain aspects of T2weighting for contrast generation with spinal fluid [59].
The IVWM prediction agreed with surgical findings in $78 \%$ of cases. The most common reason for an inaccurate pre-surgical IVWM was thrombus within the aneurysm or previous surgical instrumentation [59]. What remains unknown, and of crucial importance, is the ability of IVWM to predict future risk of IA rupture based on imaging characteristics such as wall thickness or enhancement. A retrospective study described IA wall enhancement between 31 "unstable" IAs (ruptured, symptomatic, or undergoing morphological modification) and 77 "stable" 
IAs (incidental and nonevolving) [60]. Using a 3T MRI with 3D T1 pre- and post-contrast imaging, wall enhancement was found in $87 \%$ of unstable and only $29 \%$ of the stable IAs.

Several studies have examined IVWM findings after endovascular treatment of IAs. Using standard MRI sequences, it has been identified that IA wall enhancement is common, occurring in 19-66 \% of patients treated with endovascular coiling or flow-diversion stents [61-63]. Procedural factors, such as the density of coil packing or coil material and IA-specific characteristics, such as IA size or location, influenced the incidence of wall enhancement, but the MRI findings did not predict IA occlusion success, procedural complications, or post-procedure morbidity such as IA rupture. One case report used IVWM to demonstrate thrombosis of an IA treated with a flowdiversion stent, [64] but otherwise IVWM has not been utilized to study the pathophysiology of IA occlusion following endovascular treatment.

A recently published study examined 11 patients with subarachnoid hemorrhage who had negative catheter angiograms and found that 4/11 had vessel wall enhancement on IVWM near possible sites of IA rupture, raising the possibility of ruptured or thrombosed IAs that may have been missed on luminal imaging modalities [65]. This represents an important future research direction for IVWM studies of patients with non-traumatic subarachnoid hemorrhage who have a negative initial catheter angiogram, which is $10-20 \%$ of patients $[66,67]$. The yield of repeat catheter angiography is low in this population and IVWM may allow the identification of the causative pathology and lead to management strategies that reduce future morbidity [68].

\section{Vasculitis (Fig. 3)}

Vasculitis, the result of an immune system-mediated attack on the arterial vessel wall, $[69,70]$ compromises mural integrity and leads to contrast uptake [71]. While there are numerous etiologies for intracranial vasculitis, which have different pathophysiology and temporal courses, the end result of vascular mural inflammation is consistent. Given that IVWM is particularly sensitive to vessel wall enhancement and that other diagnostic tests such as catheter angiogram or cerebrospinal fluid analysis are often inconclusive and lead to invasive brain biopsy, researchers have pursued IVWM in vasculitis. Early research demonstrated the high prevalence of vessel wall enhancement and wall thickening, reported in $23 / 27$ and $25 / 27$ patients in one series [72]. The first 3T study used 2D sequences and identified the concentric pattern of wall enhancement seen in vasculitis, as compared to the eccentric enhancement seen in atherosclerosis [46]. Although reversible cerebral vasospasm syndrome (RCVS) often resembles cerebral vasculitis on luminal imaging modalities such as
MRA or DSA [73], RCVS should exhibit very subtle or no vessel wall enhancement on IVWM as compared to vasculitis [74]. The concentric enhancement pattern of vasculitis has been replicated in subsequent studies [75], but further research is still warranted to verify this finding in a larger cohort with biopsy-proven cerebral vasculitis.

Research has identified more intense enhancement in vasculitis patients than atherosclerosis patients, which has been investigated as a therapeutic efficacy marker [76]. Case reports with longitudinal data have shown improvement of wall enhancement after treatment with immunosuppressive medications $[77,78]$, but in a study of 4 vasculitis patients there was a decrease in the intensity of enhancement with immunosuppression for $2 / 4$ patients, while in the other 2 the enhancement persisted two months after the index scan despite clinical improvement [76]. Another longitudinal study, using 2D techniques with 3T MRI, showed that on baseline imaging 9/13 vasculitis patients had smooth concentric wall enhancement with wall thickening, $3 / 13$ had eccentric wall enhancement with wall thickening and $1 / 13$ had no identifiable vessel wall abnormality [75]. Followup imaging showed variable amounts of improvement in the enhancement after treatment, with some patients continuing to enhance after a year of follow-up despite clinical improvement, highlighting the lack of consistency in follow-up imaging IVWM findings for vasculitis patients. Nonetheless, IVWM's potential role as a marker of treatment response should continue to be investigated given the lack of randomized clinical trials for vasculitis treatment and the heterogeneity of disease activity, patient response, and high rate of adverse effects associated with treatment and uncertain necessary duration of treatment.

\section{Intracranial dissection (Fig. 3)}

Arterial vessel wall dissection can be difficult to differentiate from atherosclerotic stenosis/occlusion on conventional luminal imaging modalities [79]. T1-weighted spin echo and gradient echo MRI sequences have long been used to identify the often crescentic intramural hematoma associated with dissection in the aorta, extracranial carotid and extracranial vertebral arteries [80-84]. Similar findings have been described in intracranial vessels [85-88], but inadequate resolution was a significant limitation for the diminutive intracranial vasculature [79]. Sub-millimeter resolution and suppression of intraluminal blood signal on 3T 3D IVWM allows detection of intracranial intramural hematomas and more detailed visualization of secondary features of dissection such as intimal flaps in the vessel lumen, the morphology of the false lumen, or the contours of a dissecting pseudoaneurysm [89]. 


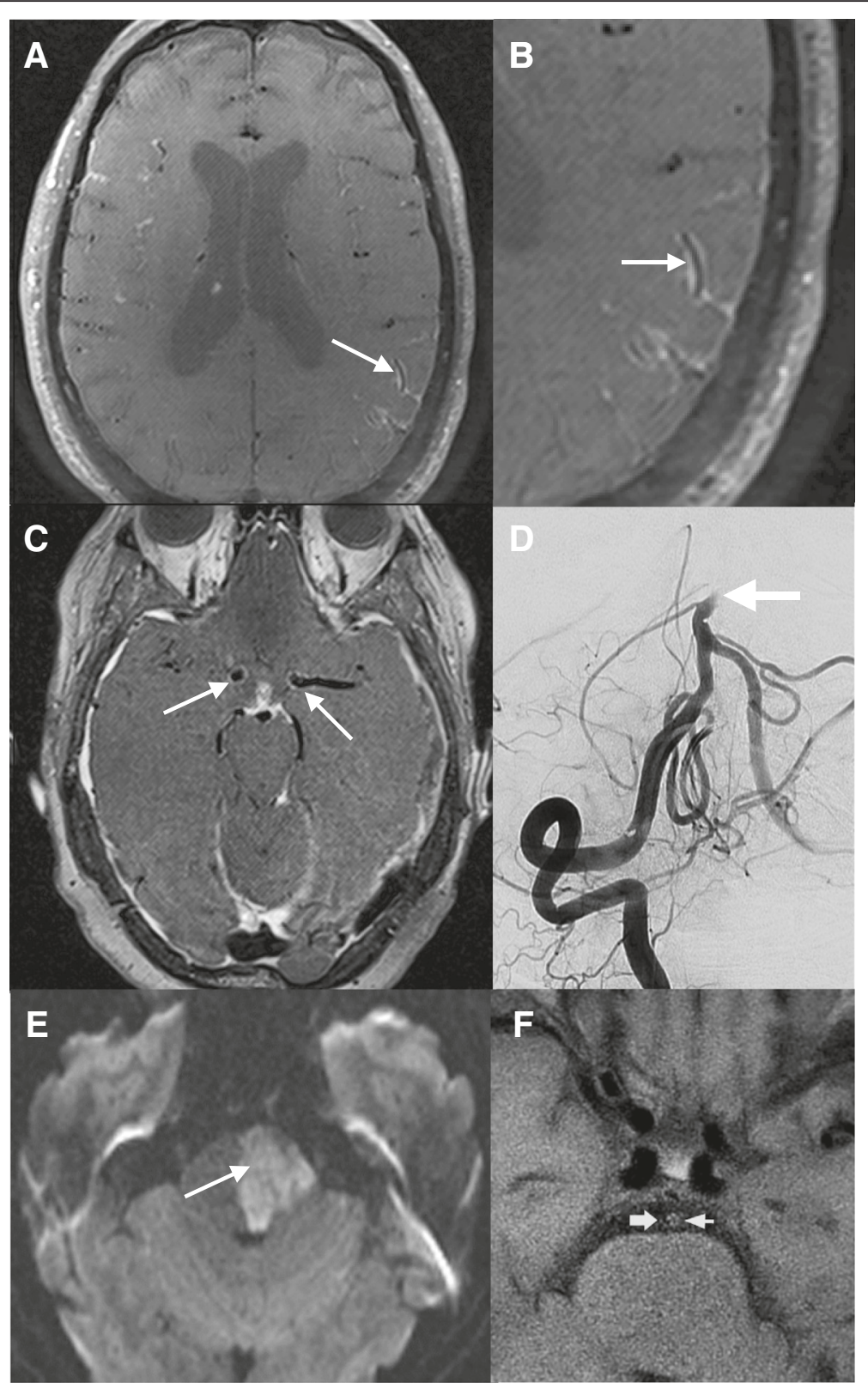

Fig. 3 a 3D axial T1-weighted post-contrast image showing the "tram track" appearance (white arrow) of a peripheral MCA branch with concentric enhancement from presumed cerebral vasculitis due to inflammatory amyloid angiopathy with adjacent leptomeningeal enhancement from recen superficial siderosis. b Higher magnification of the same patient showing the tram track appearance of concentric enhancement. c 3D axial T1-weighted post-contrast image in a second patient with bacterial meningitis and associated vasculitis, showing the concentric vessel wall enhancement in both terminal internal carotid artery segments (white arrows), which extends along the left middle cerebral artery vessel. $\mathbf{d}$ Lateral digital subtraction angiography showing a basilar artery dissection and near occlusion (minimal distal flow was seen on delayed imaging-not shown) (white arrow). e Axial diffusion-weighted image showing a pontine ischemic stroke (white arrow) which resulted from the dissection. $\mathbf{f}$ 3D axial T1-weighted image, proximal to occlusion, showing eccentric wall thickening with $\mathrm{T} 1$ hyperintense signal (short white arrow) representing arterial dissection, with the remaining patent lumen (thick arrow)

The vertebral arteries are prone to intracranial dissection, but their tortuous course, natural variation in caliber and small size make it difficult to reliably discern pathologic findings from normal variations or adjacent structures such as bone or venous plexuses [90]. Although studies have favorably compared IVWM of intracranial vertebral artery dissection to other sequences $[9,91,92]$ such as TOF MRA and other 3D techniques that do not suppress blood signal like spoiled gradient-recalled (SPGR), only one study attempted to show statistical superiority for the IVWM sequences [8]. In that study, which used a $1.5 \mathrm{~T}$ MRI and included 18 
patients with vertebral artery dissection and 12 controls, a 3D VRFA technique was statistically superior to SPGR in detecting the false lumen of the dissected artery [8].

Less has been published concerning IVWM and intracranial anterior circulation dissection. A case report described how IVWM led to stent placement in a patient with middle cerebral artery dissection and high-grade stenosis [93]. Other case reports have reported successful identification of middle and anterior cerebral artery dissection [94, 95]. None of these studies included a control group or reported rates of false negative IVWM findings, which does not provide support for the routine use of IVWM in patients suspected to have dissection. However, for patients who are strongly suspected of having intracranial dissection, such as trauma patients with cryptogenic ischemic stroke, but have negative CTA or MRA imaging, the definitive test is a digital subtraction angiogram, which carries a nontrivial risk of iatrogenic stroke or other complications [96]. Taking that into account, IVWM could be useful in this subset of patients who have had negative noninvasive screening for dissection, but a high clinical suspicion of dissection. IVWM may also be advantageous over other MRI techniques for the detection of subadventitial dissections, which may be occult on luminal imaging techniques if there is no associated luminal stenosis.

\section{Comparisons to histopathology}

Pathological studies comparing excised IAs to IVWM have generally shown excellent agreement between invivo and microscopic comparisons. Using rabbits with iatrogenic aneurysms, a study showed IA wall thickness was reliable at the dome of IA, but not the neck and at resolutions greater than one voxel, which modern scanning techniques are reducing to less than $0.5 \mathrm{~mm}$ [97]. Comparing 7T MRI on 2 patients with unruptured IAs prior to surgical clipping with histologic measurements on an ex vivo IVWM found excellent correlation for wall thickness measurements [98]. However, the study did not report other morphologic data such as wall enhancement or intramural pathology. If possible, future IVWM IA studies should include comparisons to surgical pathology, which would appear feasible given the number of patients who undergo clipping or other excision procedures, but is complicated by the difficulty of performing pathology on friable arterial vessel walls, often measuring $<0.2 \mathrm{~mm}$ [99].

In comparison to the atherosclerosis pathology studies performed for IVWM of the carotid arteries, where carotid endarterectomy provides convenient tissue samples $[100,101]$, the large and medium diameter intracranial vessels, the major sites of atherosclerosis, are not typically available for pathology prior to autopsy. ${ }^{14}$ As a result, the majority of studies comparing IVWM to intracranial atherosclerotic histopathology have used post-mortem MR acquisition. Two studies used cadaver intracranial vessel specimens to compare histopathologic findings to 7T IVWM $[102,103]$. In those studies, IVWM was accurate at identifying increased wall thickness, areas of foamy macrophages, collagen deposition, luminal stenosis, or outer wall protrusion. However, the conclusions that can be drawn from post-mortem imaging, in the absence of blood or surrounding brain parenchyma and CSF, are not definitive. In one case report, the authors performed 3T IVWM of a patient with diffuse intracranial atherosclerosis and ischemic strokes shortly before they died of pneumonia and sepsis [104]. The plaque was not thought to be symptomatic, but had fibrofatty and calcific components on IVWM that corresponded to lipid and loose matrix, fibrous tissue and calcium on histopathology [104]. Intraplaque hemorrhage was not present in that patient's sample, so comparison was not possible.

\section{Challenges with using IVWM for differentiating intracranial pathology (Fig. 4)}

Although distinctive IVWM patterns have been described, the most important factor in using IVWM for reliable differentiation of intracranial pathology is interpreting it in conjunction with clinical information, as no single IVWM imaging finding has sufficiently accurate predictive ability. For example, concentric wall enhancement, usually categorized as continuous circumferential enhancement with the width of the thinnest enhancement being $\geq 50 \%$ of the thickest segment, can be compared to eccentric enhancement, categorized as either clearly limited to one side of the vessel wall or the thinnest part of the wall enhancement being $<50 \%$ of the thickest point. Research shows that eccentric wall enhancement is present more often in intracranial atherosclerotic lesions than in autoimmune or infectious vasculitis [17]. However, concentric wall enhancement IVWM has also been reported in atherosclerotic stroke, RCVS, drug-induced vasculopathy, Graves disease and after both arterial thrombolysis and mechanical thrombectomy [20, 17, 72, 75, 105-107].

An example of how clinical information would help inform the utility of IVWM would be moyamoya disease, which would be expected to be more common in Asian patients with few vascular risk factors [108]. Angiographic imaging findings of moyamoya disease have been described as severely narrowed or occluded arteries of the proximal anterior circulation with extensive collateralization. Moyamoya disease can have similar IVWM findings to vasculitis such as mild concentric enhancement, but confined to the locations favored by the disease - distal ICA and the M1/A1 segments; or moyamoya can display stenosis alone without enhancement [7, 109]. Additional findings 


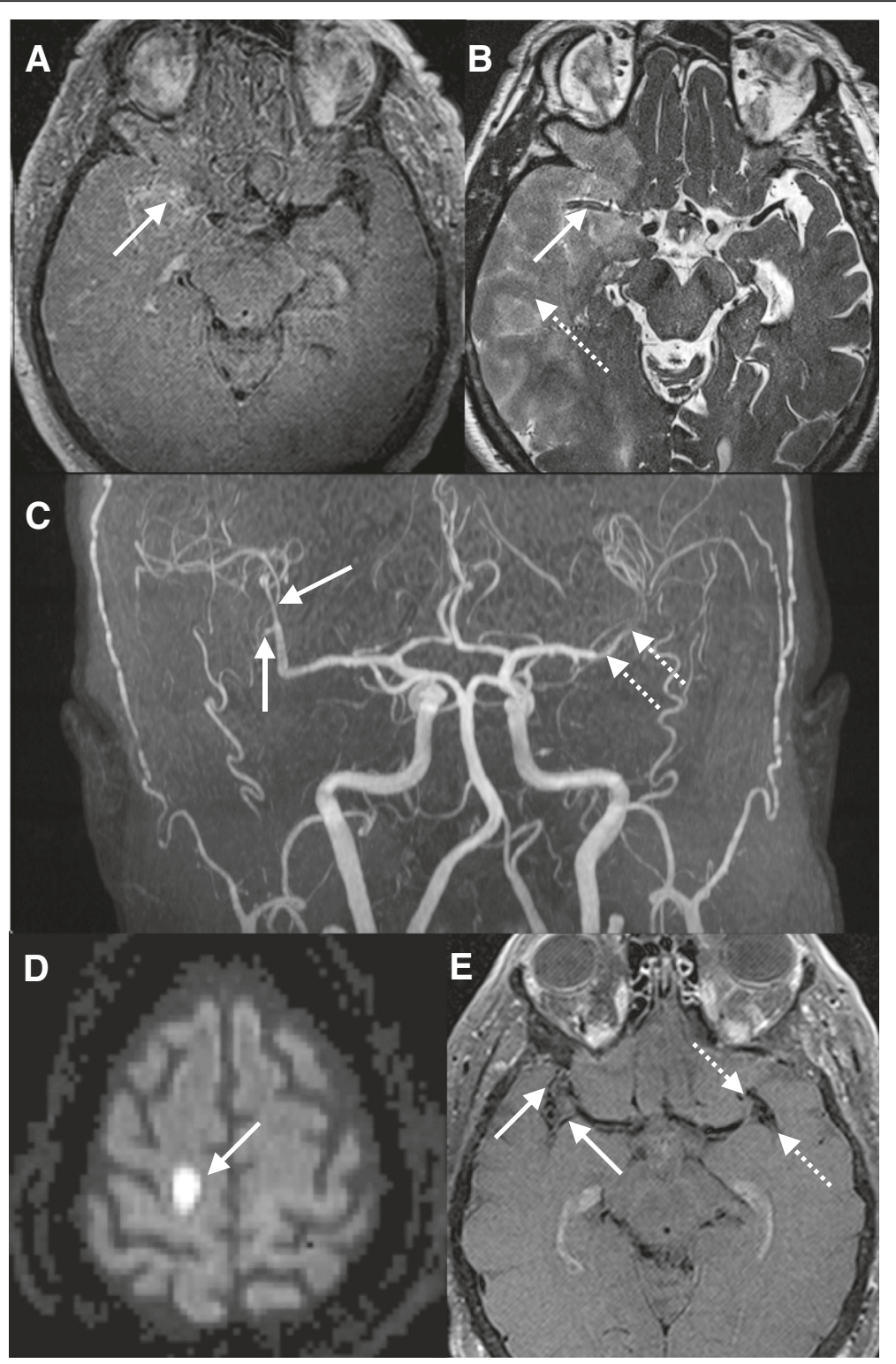

Fig. 4 a 3D axial T1-weighted post-contrast image showing diffuse vessel wall and luminal enhancement (white arrow) of the right M1 segment in a patient with left-sided weakness, sensory loss and neglect. b 3D axial T2-weighted image of the same section of the right M1 segment with hyperintense signal in the vessel lumen, consistent with occlusive thrombus from recently diagnosed atrial fibrillation, resulting in a large right MCA territory ischemic stroke (dotted white arrow). c Anterior-posterior digital subtraction angiogram in a second patient who presented with post-coital headache and was found to have multifocal luminal narrowing in the bilateral M2 branches (dotted and solid white arrows). d Axial diffusion-weighted image showing a right hemisphere ischemic stroke in the same patient. e 3D axial T1-weighted post-contrast image showing the absence of vessel wall enhancement at the $\mathrm{M} 2$ segments corresponding to the narrowing seen on the angiogram in image (c), consistent with reversible cerebral vasoconstriction syndrome, which should result in very subtle or no enhancement of the vessel wall at sites of vasospastic narrowing

include absence of wall thickening, collateralization and homogenous signal intensity of the arterial wall [110]. Other imaging features more common in moymoya disease include lack of eccentric lesions and focal enhancement, which help enable differentiation of moyamoya disease from intracranial atherosclerosis and other inflammatory etiologies $[46,109]$.
Imaging features of intracranial dissection, although exhibiting a pattern of eccentric wall thickening and intimal flap enhancement appearing similar to atherosclerosis, additionally often include crescentic mural T1 pre-contrast hyperintensity representing methemoglobin [46], which is less common and more superficial in intracranial atherosclerotic with intraplaque hemorrhage. 
IVWM has also been used to differentiate vertebral and basilar artery hypoplasias from atherosclerosis based on the lack of wall thickening at a stenosis seen in hypoplasia $[111,112]$. This may help predict the natural history of such lesions and inform the need for interventional angioplasty in patients with recurrent stroke despite maximal medical therapy.

Multicontrast IVWM, combining T1- with T2-weighted and other sequences, may also prove useful in differentiation of atherosclerosis, RCVS and vasculitis; diagnoses that can require costly or invasive workups $[17,74,75]$. The multicontrast approach will help to minimize the reliance on vessel wall enhancement for pathologic differentiation, which varies in duration in most published research and does not necessarily correlate with disease activity [75]. Indeed, a case report of radiation-induced vasculopathy described persistent IVWM concentric enhancement 2 years following the radiation exposure [113]. Using a multicontrast approach, future researchers can also unravel the natural history of the different intracranial pathologies seen on IVWM and ultimately develop protocols with sequences capable of reliably differentiating a diverse spectrum of intracranial pathology.

\section{Conclusion}

IVWM is not currently in wide clinical use, but the conditions for this transition are in place. 2D black blood IVWM techniques are readily available on all MRIs and can be performed at high resolution on 3T systems. All major MRI manufacturers have a 3D VRFA sequence that can be used at 3T, available as either a research or product sequence depending on the scanner make and model, allowing for black blood intracranial imaging with the requisite ability to construct multiplanar images with isotropic sub-millimeter resolution. At a minimum a TOF MRA and T1- or PD-weighted sequence with pre- and post-contrast imaging is required for IVWM, although additional information can be obtained by including a T2-weighted sequence and, in certain clinical scenarios, a 3D T1-weighted gradient echo sequence optimized for the detection of mural hemorrhage such as MP-RAGE. Overall scan time can be less than $30 \mathrm{~min}$ and incorporated into the billing format of a conventional MRA with contrast. While the current literature does not support conclusive delineation of intracranial pathology, IVWM allows radiologists to provide clinicians with important insights given the challenging clinical scenarios where IVWM is indicated, such as differentiating between vasculitis, RCVS and atherosclerosis.

Future research will clarify if the unique morphological findings seen on IVWM, such as unruptured IA enhancement or atherosclerotic plaque fibrous cap rupture, can predict future risk of morbidity and mortality from aneurysm rupture or ischemic stroke. There are ongoing prospective longitudinal studies that will begin to answer these questions and others, such as the ability of these morphological features to identify patients who would benefit from different management strategies. In this regard, IVWM has tremendous future potential to identify patients for clinical trials and as a surrogate biomarker outcome.

\begin{abstract}
Abbreviations
BA, basilar artery; CSF, cerebrospinal fluid; CTA, computed tomography angiography; DANTE, delay alternating with nutation for tailored excitation; DWI, diffusion-weigthed imaging; IA, intracranial aneurysm; IPH, intraplaque hemorrhage; IMWM, intracranial vessel wall MRI; MCA, middle cerebral artery; MP-RAGE, magnetization-prepared rapid gradient-echo; MRA, magnetic resonance angiography; $M S D E$, motion sensitized driven equilibrium; $P D$, proton density; RCVS, reversible cerebral vasoconstriction syndrome; TOF, time-of-flight; VRFA, variable refocusing flip angle
\end{abstract}

\section{Acknowledgements}

None.

\section{Funding sources}

This publication was supported by the National Center for Advancing Translational Sciences of the National Institutes of Health under Award Number KL2TR001065. The content is solely the responsibility of the authors and does not necessarily represent the official views of the National Institutes of Health.

\section{Authors' contributions}

$A D, L C, M P$, and MMB helped conceive of the review, all drafted sections of the manuscript, helped edit it, and gave final approval.

\section{Competing interests}

The authors declare that they have no competing interests.

\section{Ethics approval and consent to participate}

There were no human subjects in this review article, so we did not seek approval from an ethics committee or institutional review board.

\section{Disclosures \\ None.}

\section{Author details}

'Department of Neurology, University of Utah, Salt Lake City, USA. ${ }^{2}$ Department of Neurosurgery, University of Utah, Salt Lake City, USA.

${ }^{3}$ Department of Radiology, University of Washington, Seattle, USA.

Received: 4 February 2016 Accepted: 23 May 2016

Published online: 02 June 2016

\section{References}

1. Jain K. Some observations on the anatomy of the middle cerebral artery. Can J Surg. 1964;7:134-9.

2. Qiao Y, Steinman DA, Qin Q, Etesami M, Schär M, Astor BC, et al. Intracranial arterial wall imaging using three-dimensional high isotropic resolution black blood MRI at 3.0 Tesla. J Magn Reson Imaging JMRI. 2011;34:22-30.

3. Crowe LA, Gatehouse P, Yang GZ, Mohiaddin RH, Varghese A, Charrier C, et al. Volume-selective 3D turbo spin echo imaging for vascular wall imaging and distensibility measurement. J Magn Reson Imaging JMRI. 2003;17:572-80

4. Qiao Y, Zeiler SR, Mirbagheri S, Leigh R, Urrutia V, Wityk R, et al. Intracranial plaque enhancement in patients with cerebrovascular events on highspatial-resolution MR images. Radiology. 2014;271:534-42.

5. Natori T, Sasaki M, Miyoshi M, Ohba H, Katsura N, Yamaguchi M, et al. Evaluating middle cerebral artery atherosclerotic lesions in acute ischemic stroke using magnetic resonance T1-weighted 3-dimensional vessel wall imaging. J Stroke Cerebrovasc Dis. 2014;23:706-11. 
6. Portanova A, Hakakian N, Mikulis DJ, Virmani R, Abdalla WMA, Wasserman BA. Intracranial vasa vasorum: insights and implications for imaging. Radiology. 2013;267:667-79.

7. Ryoo S, Cha J, Kim SJ, Choi JW, Ki C-S, Kim KH, et al. High-resolution magnetic resonance wall imaging findings of Moyamoya disease. Stroke J Cereb Circ. 2014:45:2457-60.

8. Sakurai K, Miura T, Sagisaka T, Hattori M, Matsukawa N, Mase M, et al. Evaluation of luminal and vessel wall abnormalities in subacute and other stages of intracranial vertebrobasilar artery dissections using the volume isotropic turbo-spin-echo acquisition (VISTA) sequence: a preliminary study. J Neuroradiol J Neuroradiol. 2013:40:19-28.

9. Takano K, Yamashita S, Takemoto K, Inoue T, Kuwabara Y, Yoshimitsu K. MRI of intracranial vertebral artery dissection: evaluation of intramural haematoma using a black blood, variable-flip-angle 3D turbo spin-echo sequence. Neuroradiology. 2013;55:845-51.

10. Wang J, Helle M, Zhou Z, Börnert P, Hatsukami TS, Yuan C. Joint blood and cerebrospinal fluid suppression for intracranial vessel wall MRI. Magn Reson Med Off J Soc Magn Reson Med Soc Magn Reson Med. 2015;75:831-8.

11. Xie Y, Yang Q, Xie G, Pang J, Fan Z, Li D. Improved black-blood imaging using DANTE-SPACE for simultaneous carotid and intracranial vessel wall evaluation. Magn Reson Med. 2015.

12. Zhang L, Zhang N, Wu J, Zhang L, Huang Y, Liu X, et al. High resolution three dimensional intracranial arterial wall imaging at 3T using T1 weighted SPACE. Magn Reson Imaging. 2015;33:1026-34.

13. Wang J, Zhao X, Yamada K, et al. High-risk mid-cerebral artery atherosclerotic disease detection using Simultaneous Non-contrast Angiography and intraPlaque khemorrhage (SNAP) imaging. Proceedings of the International Society of Magnetic Resonance in Medicine. Salt Lake City, UT, USA; 2013

14. Antiga L, Wasserman BA, Steinman DA. On the overestimation of early wall thickening at the carotid bulb by black blood MRI, with implications for coronary and vulnerable plaque imaging. Magn Reson Med. 2008;60:1020-8.

15. Busse RF, Brau ACS, Vu A, Michelich CR, Bayram E, Kijowski R, et al. Effects of refocusing flip angle modulation and view ordering in 3D fast spin echo. Magn Reson Med. 2008;60:640-9.

16. Fan Z, Zhang Z, Chung Y-C, Weale P, Zuehlsdorff S, Carr J, et al. Carotid arterial wall MRI at 3T using 3D variable-flip-angle turbo spin-echo (TSE) with flowsensitive dephasing (FSD). J Magn Reson Imaging JMRI. 2010;31:645-54.

17. Mossa-Basha M, Hwang WD, De Havenon A, Hippe D, Balu N, Becker K, et al. Multicontrast high-resolution vessel wall magnetic resonance imaging and its value in differentiating intracranial vasculopathic processes. Stroke J Cereb Circ. 2015;46:1567-73.

18. Zhu C, Graves MJ, Yuan J, Sadat U, Gillard JH, Patterson AJ. Optimization of improved motion-sensitized driven-equilibrium (iMSDE) blood suppression for carotid artery wall imaging. J Cardiovasc Magn Reson Off J Soc Cardiovasc Magn Reson. 2014;16:61.

19. Yang Y, Liu F, Xu W, Crozier S. Compressed sensing MRI via two-stage reconstruction. IEEE Trans Biomed Eng. 2015;62:110-8.

20. Franke $P$, Markl M, Heinzelmann S, Vaith $P$, Bürk J, Langer $M$, et al. Evaluation of a 32-channel versus a 12-channel head coil for high-resolution postcontrast MRI in giant cell arteritis (GCA) at 3T. Eur J Radiol. 2014;83:1875-80.

21. Yang H, Zhu Y, Geng Z, Li C, Zhou L, Liu Ql. Clinical value of black-blood high-resolution magnetic resonance imaging for intracranial atherosclerotic plaques. Exp Ther Med. 2015;10:231-6.

22. Kim SM, Ryu C-W, Jahng G-H, Kim EJ, Choi WS. Two different morphologies of chronic unilateral middle cerebral artery occlusion: evaluation using highresolution MRI. J Neuroimaging Off J Am Soc Neuroimaging. 2014;24:460-6.

23. Hui FK, Zhu X, Jones SE, Uchino K, Bullen JA, Hussain MS, et al. Early experience in high-resolution MRI for large vessel occlusions. J Neurointerventional Surg. 2015;7:509-16

24. Klein IF, Lavallée PC, Touboul PJ, Schouman-Claeys E, Amarenco P. In vivo middle cerebral artery plaque imaging by high-resolution MRI. Neurology. 2006:67:327-9.

25. Kim YS, Lim S-H, Oh K-W, Kim JY, Koh S-H, Kim J, et al. The advantage of high-resolution MRI in evaluating basilar plaques: a comparison study with MRA. Atherosclerosis. 2012;224:411-6.

26. de Havenon A, Yuan C, Tirschwell D, Hatsukami T, Anzai Y, Becker K, et al. Nonstenotic culprit plaque: the utility of high-resolution vessel wall mri of intracranial vessels after ischemic stroke. Case Rep Radiol. [Internet]. 2015 [cited 2015 Sep 18];2015. Available from: http://www.ncbi.nlm.nih.gov/pmc/ articles/PMC4543789/.
27. Sui $B$, Gao $P$, Lin $Y$, Jing $L$, Qin $H$. Distribution and features of middle cerebral artery atherosclerotic plaques in symptomatic patients: a 3.0 T high-resolution MRI study. Neurol Res. 2015;37:391-6.

28. Zhao D-L, Deng G, Xie B, Ju S, Yang M, Chen X-H, et al. High-resolution MRI of the vessel wall in patients with symptomatic atherosclerotic stenosis of the middle cerebral artery. J Clin Neurosci Off J Neurosurg Soc Australas. 2015;22:700-4

29. Chung GH, Kwak HS, Hwang SB, Jin GY. High resolution MR imaging in patients with symptomatic middle cerebral artery stenosis. Eur J Radiol. 2012;81:4069-74.

30. Xu W-H, Li M-L, Niu J-W, Feng F, Jin Z-Y, Gao S. Intracranial artery atherosclerosis and lumen dilation in cerebral small-vessel diseases: a high-resolution MRI Study. CNS Neurosci Ther. 2014;20:364-7.

31. Xu W-H, Li M-L, Gao S, Ni J, Zhou L-X, Yao M, et al. Plaque distribution of stenotic middle cerebral artery and its clinical relevance. Stroke. 2011:42:2957-9.

32. Kim BJ, Yoon Y, Lee D-H, Kang D-W, Kwon SU, Kim JS. The shape of middle cerebral artery and plaque location: high-resolution MRI finding. Int J Stroke Off J Int Stroke Soc. 2015;10:856-60.

33. Xu W-H, Li M-L, Gao S, Ni J, Zhou L-X, Yao M, et al. In vivo high-resolution MR imaging of symptomatic and asymptomatic middle cerebral artery atherosclerotic stenosis. Atherosclerosis. 2010;212:507-11.

34. Nishioka T, Luo H, Eigler NL, Berglund H, Kim C-J, Siegel RJ. Contribution of inadequate compensatory enlargement to development of human coronary artery stenosis: An in vivo intravascular ultrasound study. J Am Coll Cardiol. 1996;27:1571-6.

35. Schoenhagen P, Ziada KM, Kapadia SR, Crowe TD, Nissen SE, Tuzcu EM. Extent and direction of arterial remodeling in stable versus unstable coronary syndromes an intravascular ultrasound study. Circulation. 2000;101:598-603.

36. Klein IF, Lavallée PC, Mazighi M, Schouman-Claeys E, Labreuche J, Amarenco P. Basilar artery atherosclerotic plaques in paramedian and lacunar pontine infarctions: a high-resolution MRI study. Stroke J Cereb Circ. 2010;41:1405-9.

37. Lim S-H, Choi H, Kim H-T, Kim J, Heo SH, Chang D, et al. Basilar plaque on high-resolution MRI predicts progressive motor deficits after pontine infarction. Atherosclerosis. 2015:240:278-83.

38. Saam T, Hetterich $H$, Hoffmann V, Yuan C, Dichgans M, Poppert $H$, et al. Meta-analysis and systematic review of the predictive value of carotid plaque hemorrhage on cerebrovascular events by magnetic resonance imaging. J Am Coll Cardiol. 2013;62:1081-91.

39. McNally JS, Kim S-E, Yoon H-C, Findeiss LK, Roberts JA, Nightingale DR, et al. Carotid magnetization-prepared rapid acquisition with gradient-echo signal is associated with acute territorial cerebral ischemic events detected by diffusion-weighted MRI. Circ Cardiovasc Imaging. 2012;5:376-82.

40. McNally JS, McLaughlin MS, Hinckley PJ, Treiman SM, Stoddard GJ, Parker $\mathrm{DL}$, et al. Intraluminal thrombus, intraplaque hemorrhage, plaque thickness, and current smoking optimally predict carotid stroke. Stroke J Cereb Circ. 2015;46:84-90.

41. Ota H, Yarnykh VL, Ferguson MS, Underhill HR, Demarco JK, Zhu DC, et al. Carotid intraplaque hemorrhage imaging at 3.0-T MR imaging: comparison of the diagnostic performance of three T1-weighted sequences. Radiology. 2010;254:551-63.

42. Ryu C-W, Jahng G-H, Kim E-J, Choi W-S, Yang D-M. High resolution wall and lumen MRI of the middle cerebral arteries at 3 tesla. Cerebrovasc Dis Basel Switz. 2009:27:433-42.

43. Vakil P, Ansari SA, Cantrell CG, Eddleman CS, Dehkordi FH, Vranic J, et al. Quantifying intracranial aneurysm wall permeability for risk assessment using dynamic contrast-enhanced MRI: a pilot study. AJNR Am J Neuroradiol. 2015:36:953-9.

44. Kim J, Jung K, Sohn C, Moon J, Han M, Roh J. Middle cerebral artery plaque and prediction of the infarction pattern. Arch Neurol. 2012;69:1470-5.

45. Yu JH, Kwak HS, Chung GH, Hwang SB, Park MS, Park SH. Association of intraplaque hemorrhage and acute infarction in patients with basilar artery plaque. Stroke J Cereb Circ. 2015:46:2768-72.

46. Swartz RH, Bhuta SS, Farb Rl, Agid R, Willinsky RA, terBrugge KG, et al. Intracranial arterial wall imaging using high-resolution 3-tesla contrast-enhanced MRI. Neurology. 2009;72:627-34.

47. Skarpathiotakis M, Mandell DM, Swartz RH, Tomlinson G, Mikulis DJ. Intracranial atherosclerotic plaque enhancement in patients with ischemic stroke. Am J Neuroradiol. 2013:34:299-304.

48. Kim J-M, Jung K-H, Sohn C-H, Moon J, Shin J-H, Park J, et al. Intracranial plaque enhancement from high resolution vessel wall magnetic resonance imaging predicts stroke recurrence. Int J Stroke. 2016;11:171-9. 
49. Yang W-Q, Huang B, Liu X-T, Liu H-J, Li P-J, Zhu W-Z. Reproducibility of high-resolution MRI for the middle cerebral artery plaque at 3T. Eur J Radiol. 2014;83:e49-55.

50. Kasner SE, Chimowitz MI, Lynn MJ, Howlett-Smith H, Stern BJ, Hertzberg VS, et al. Predictors of ischemic stroke in the territory of a symptomatic intracranial arterial stenosis. Circulation. 2006:113:555-63.

51. Hong K-S, Yegiaian S, Lee M, Lee J, Saver JL. Declining stroke and vascular event recurrence rates in secondary prevention trials over the past 50 years and consequences for current trial design. Circulation. 2011;123:2111-9.

52. Matouk CC, Mandell DM, Günel M, Bulsara KR, Malhotra A, Hebert R, et al. Vessel wall magnetic resonance imaging identifies the site of rupture in patients with multiple intracranial aneurysms: proof of principle. Neurosurgery. 2013:72:492-6. discussion 496

53. Nagahata S, Nagahata M, Obara M, Kondo R, Minagawa N, Sato S, Sato S, Mouri W, Saito S, Kayama T. Wall enhancement of the intracranial aneurysms revealed by magnetic resonance vessel wall imaging using three-dimensional turbo spin-echo sequence with motion-sensitized drivenequilibrium: a sign of ruptured aneurysm? Clin Neuroradiol. 2014.

54. Kaminogo M, Yonekura M, Shibata S. Incidence and outcome of multiple intracranial aneurysms in a defined population. Stroke. 2003;34:16-21.

55. Navalitloha Y, Taechoran C, O'Chareon S. Multiple intracranial aneurysms: incidence and management outcome in King Chulalongkorn Memorial Hospital. J Med Assoc Thail Chotmaihet Thangphaet. 2000;83:1442-6.

56. Park S, Lee DH, Ryu C-W, Pyun HW, Choi CG, Kim SJ, et al. Incidental saccular aneurysms on head MR angiography: 5 Years' experience at a single largevolume center. J Stroke. 2014;16:189-94.

57. Chalouhi N, Ali MS, Jabbour PM, Tjoumakaris SI, Gonzalez LF, Rosenwasser $\mathrm{RH}$, et al. Biology of intracranial aneurysms: role of inflammation. J Cereb Blood Flow Metab. 2012;32:1659-76.

58. Park JK, Lee CS, Sim KB, Huh JS, Park JC. Imaging of the walls of saccular cerebral aneurysms with double inversion recovery black-blood sequence. J Magn Reson Imaging. 2009;30:1179-83.

59. Tenjin H, Tanigawa S, Takadou M, Ogawa T, Mandai A, Nanto M, et al. Relationship between preoperative magnetic resonance imaging and surgical findings: aneurysm wall thickness on high-resolution T1-weighted imaging and contact with surrounding tissue on steady-state free precession imaging. Neurol Med Chir (Tokyo). 2013;53:336-42.

60. Edjlali M, Gentric J-C, Régent-Rodriguez C, Trystram D, Hassen WB, Lion S, et al. Does aneurysmal wall enhancement on vessel wall MRI help to distinguish stable from unstable intracranial aneurysms? Stroke J Cereb Circ. 2014;45:3704-6.

61. Su I-C, Willinsky RA, Fanning NF, Agid R. Aneurysmal wall enhancement and perianeurysmal edema after endovascular treatment of unruptured cerebral aneurysms. Neuroradiology. 2014;56:487-95.

62. McGuinness BJ, Memon S, Hope JK. Prospective study of early MRI appearances following flow-diverting stent placement for intracranial aneurysms. AJNR Am J Neuroradiol. 2015:36:943-8.

63. Fanning NF, Willinsky RA, terBrugge KG. Wall enhancement, edema, and hydrocephalus after endovascular coil occlusion of intradural cerebral aneurysms. J Neurosurg. 2008;108:1074-86.

64. Gory B, Sigovan M, Vallecilla C, Courbebaisse G, Turjman F. High-resolution MRI visualization of aneurysmal thrombosis after flow diverter stent placement. J Neuroimaging. 2015;25:310-1.

65. Coutinho JM, Sacho RH, Schaafsma JD, Agid R, Krings T, Radovanovic I, Matouk CC, Mikulis DJ, Mandell DM. High-Resolution Vessel Wall Magnetic Resonance Imaging in Angiogram-Negative Non-Perimesencephalic Subarachnoid Hemorrhage. Clin Neuroradiol. 2015.

66. Khan AA, Smith JDS, Kirkman MA, Robertson FJ, Wong K, Dott C, et al. Angiogram negative subarachnoid haemorrhage: outcomes and the role of repeat angiography. Clin Neurol Neurosurg. 2013;115:1470-5.

67. Lin N, Zenonos G, Kim AH, Nalbach SV, Du R, Frerichs KU, et al. Angiogramnegative subarachnoid hemorrhage: relationship between bleeding pattern and clinical outcome. Neurocrit Care. 2012;16:389-98.

68. Yu D-W, Jung Y-J, Choi B-Y, Chang C-H. Subarachnoid hemorrhage with negative baseline digital subtraction angiography: is repeat digital subtraction angiography necessary? J Cerebrovasc Endovasc Neurosurg. 2012;14:210-5.

69. Lh C. Vasculitis of the central nervous system. Rheum Dis Clin North Am. 1995;21:1059-76

70. Haij-Ali RA, Calabrese LH. Primary Central Nervous System Vasculitis. In: MS GSHM, MD CMW, MHS CALM, MD JJG, editors. Inflamm. Dis. Blood Vessels
[Internet]. Wiley-Blackwell; 2012 [cited 2015 Dec 30]. p. 322-31. Available from: http://onlinelibrary.wiley.com/doi/10.1002/9781118355244.ch29/summary.

71. Bley TA, Wieben O, Vaith P, Schmidt D, Ghanem NA, Langer M. Magnetic resonance imaging depicts mural inflammation of the temporal artery in giant cell arteritis. Arthritis Care Res. 2004;51:1062-3.

72. Küker W, Gaertner S, Nagele T, Dopfer C, Schoning M, Fiehler J, et al. Vessel wall contrast enhancement: a diagnostic sign of cerebral vasculitis. Cerebrovasc Dis Basel Switz. 2008:26:23-9.

73. Miller TR, Shivashankar R, Mossa-Basha M, Gandhi D. Reversible cerebral vasoconstriction syndrome, part 2: diagnostic work-up, imaging evaluation, and differential diagnosis. AJNR Am J Neuroradiol. 2015;36:1580-8.

74. Mandell DM, Matouk CC, Farb Rl, Krings T, Agid R, TerBrugge K, et al. Vessel wall MRI to differentiate between reversible cerebral vasoconstriction syndrome and central nervous system vasculitis preliminary results. Stroke. 2012:43:860-2.

75. Obusez EC, Hui F, Hajj-Ali RA, Cerejo R, Calabrese LH, Hammad T, et al. High-resolution MRI vessel wall imaging: spatial and temporal patterns of reversible cerebral vasoconstriction syndrome and central nervous system vasculitis. AJNR Am J Neuroradiol. 2014;35:1527-32.

76. Pfefferkorn T, Linn J, Habs M, Opherk C, Cyran C, Ottomeyer C, et al. Black blood MRI in suspected large artery primary angiitis of the central nervous system. J Neuroimaging Off J Am Soc Neuroimaging. 2013;23:379-83.

77. Noh HJ, Choi JW, Kim JP, Moon GJ, Bang OY. Role of high-resolution magnetic resonance imaging in the diagnosis of primary angiitis of the central nervous system. J Clin Neurol Seoul Korea. 2014;10:267-71.

78. Saam T, Habs M, Pollatos O, Cyran C, Pfefferkorn T, Dichgans M, et al. Highresolution black-blood contrast-enhanced T1 weighted images for the diagnosis and follow-up of intracranial arteritis. Br J Radiol. 2010;83:e182-4.

79. Naggara O, Oppenheim C, Louillet F, Touzé E, Mas J-L, Leclerc X, et al. Traumatic intracranial dissection: mural hematoma on high-resolution MRI. J Neuroradiol J Neuroradiol. 2010;37:136-7.

80. Schievink WI. Spontaneous dissection of the carotid and vertebral arteries. N Engl J Med. 2001;344:898-906.

81. Flis CM, Jäger HR, Sidhu PS. Carotid and vertebral artery dissections: clinical aspects, imaging features and endovascular treatment. Eur Radiol. 2007;17:820-34.

82. Vertinsky AT, Schwartz NE, Fischbein NJ, Rosenberg J, Albers GW, Zaharchuk G. Comparison of multidetector CT angiography and MR imaging of cervical artery dissection. AJNR Am J Neuroradiol. 2008;29:1753-60.

83. Baliga RR, Nienaber CA, Bossone E, Oh JK, Isselbacher EM, Sechtem U, et al. The role of imaging in aortic dissection and related syndromes. JACC CardiovasC Imaging. 2014;7:406-24.

84. Ben Hassen W, Machet A, Edjali-Goujon M, Legrand L, Ladoux A, Mellerio C, et al. Imaging of cervical artery dissection. Diagn Interv Imaging. 2014;95:1151-61.

85. Ohkuma H, Suzuki S, Kikkawa T, Shimamura N. Neuroradiologic and clinical features of arterial dissection of the anterior cerebral artery. AJNR Am J Neuroradiol. 2003:24:691-9.

86. Hosoya T, Adachi M, Yamaguchi K, Haku T, Kayama T, Kato T. Clinical and neuroradiological features of intracranial vertebrobasilar artery dissection. Stroke. 1999;30:1083-90.

87. Ohkuma H, Suzuki S, Shimamura N, Nakano T. Dissecting aneurysms of the middle cerebral artery: neuroradiological and clinical features. Neuroradiology. 2003:45:143-8.

88. Kurino M, Yoshioka S, Ushio Y. Spontaneous dissecting aneurysms of anterior and middle cerebral artery associated with brain infarction: a case report and review of the literature. Surg Neurol. 2002;57:428-36.

89. Chun DH, Kim ST, Jeong YG, Jeong HW. High-resolution magnetic resonance imaging of intracranial vertebral artery dissecting aneurysm for planning of endovascular treatment. J Korean Neurosurg Soc. 2015;58:155-8.

90. Naggara O, Louillet F, Touzé E, Roy D, Leclerc X, Mas J-L, et al. Added value of high-resolution MR imaging in the diagnosis of vertebral artery dissection. Am J Neuroradiol. 2010;31:1707-12.

91. Han M, Rim N-J, Lee JS, Kim SY, Choi JW. Feasibility of high-resolution MR imaging for the diagnosis of intracranial vertebrobasilar artery dissection. Eur Radiol. 2014;24:3017-24.

92. Chung J-W, Kim BJ, Choi BS, Sohn CH, Bae H-J, Yoon B-W, et al. High-resolution magnetic resonance imaging reveals hidden etiologies of symptomatic vertebral arterial lesions. J Stroke Cerebrovasc Dis Off J Natl Stroke Assoc. 2014;23:293-302.

93. Lee H-O, Kwak H-S, Chung G-H, Hwang S-B. Diagnostic usefulness of high resolution cross sectional MRI in symptomatic middle cerabral arterial dissection. J Korean Neurosurg Soc. 2011;49:370. 
94. Kwak HS, Hwang SB, Chung GH, Jeong S-K. High-resolution magnetic resonance imaging of symptomatic middle cerebral artery dissection. J Stroke Cerebrovasc Dis Off J Natl Stroke Assoc. 2014;23:550-3.

95. Chen $\mathrm{H}, \mathrm{Li}$ Z, Luo B, Zeng J. Anterior cerebral artery dissection diagnosed using high-resolution MRI. Neurology. 2015;85:481.

96. Cloft HJ, Joseph GJ, Dion JE. Risk of cerebral angiography in patients with subarachnoid hemorrhage, cerebral aneurysm, and arteriovenous malformation a meta-analysis. Stroke. 1999;30:317-20.

97. Sherif C, Kleinpeter G, Loyoddin M, Mach G, Plasenzotti R, Haider T, et al. Aneurysm wall thickness measurements of experimental aneurysms: in vivo high-field MR imaging versus direct microscopy. Acta Neurochir Suppl. 2015;120:17-20.

98. Kleinloog R, Korkmaz E, Zwanenburg JJM, Kuijf HJ, Visser F, Blankena R, et al. Visualization of the aneurysm wall: a 7.0-tesla magnetic resonance imaging study. Neurosurgery. 2014;75:614-22. discussion 622

99. Cahill J, Zhang JH. Subarachnoid hemorrhage is It time for a new direction? Stroke. 2009:40:586-7.

100. Yuan C, Mitsumori LM, Ferguson MS, Polissar NL, Echelard D, Ortiz G, et al. In vivo accuracy of multispectral magnetic resonance imaging for identifying lipid-rich necrotic cores and intraplaque hemorrhage in advanced human carotid plaques. Circulation. 2001;104:2051-6.

101. Mitsumori LM, Hatsukami TS, Ferguson MS, Kerwin WS, Cai J, Yuan C. In vivo accuracy of multisequence MR imaging for identifying unstable fibrous caps in advanced human carotid plaques. J Magn Reson Imaging JMRI. 2003;17:410-20.

102. van der Kolk AG, Zwanenburg JJM, Denswil NP, Vink A, Spliet WGM, Daemen MJ AP, et al. Imaging the intracranial atherosclerotic vessel wall using 7T MRI: initial comparison with histopathology. AJNR Am J Neuroradiol. 2015;36:694-701.

103. Majidi S, Sein J, Watanabe M, Hassan AE, Van de Moortele P-F, Suri MFK, et al. Intracranial-derived atherosclerosis assessment: an in vitro comparison between virtual histology by intravascular ultrasonography, $7 \mathrm{~T} \mathrm{MRI}$, and histopathologic findings. AJNR Am J Neuroradiol. 2013;34:2259-64.

104. Turan TN, Rumboldt Z, Granholm A-C, Columbo L, Welsh CT, Lopes-Virella $M F$, et al. Intracranial atherosclerosis: correlation between in-vivo 3T high resolution MRI and pathology. Atherosclerosis. 2014;237:460-3.

105. Yin J, Zhu J, Huang D, Shi C, Guan Y, Zhou L, et al. Unilateral symptomatic intracranial arterial stenosis and myopathy in an adolescent with Graves disease: a case report of an high-resolution magnetic resonance imaging study. J Stroke Cerebrovasc Dis Off J Natl Stroke Assoc. 2015;24:e49-52.

106. Guerrero WR, Dababneh H, Hedna S, Johnson JA, Peters K, Waters MF. Vessel wall enhancement in herpes simplex virus central nervous system vasculitis. J Clin Neurosci Off J Neurosurg Soc Australas. 2013;20:1318-9.

107. Power S, Matouk C, Casaubon LK, Silver FL, Krings T, Mikulis DJ, et al. Vessel wall magnetic resonance imaging in acute ischemic stroke: effects of embolism and mechanical thrombectomy on the arterial wall. Stroke J Cereb Circ. 2014:45:2330-4.

108. Ahn S-H, Lee J, Kim Y-J, Kwon SU, Lee D, Jung S-C, et al. Isolated MCA disease in patients without significant atherosclerotic risk factors: a highresolution magnetic resonance imaging study. Stroke J Cereb Circ. 2015; 46:697-703.

109. Kim J-M, Jung K-H, Sohn C-H, Park J, Moon J, Han MH, et al. High-resolution MR technique can distinguish moyamoya disease from atherosclerotic occlusion. Neurology. 2013;80:775-6.

110. Yuan M, Liu Z, Wang Z, Li B, Xu L, Xiao X. High-resolution MR imaging of the arterial wall in moyamoya disease. Neurosci Lett. 2015;584:77-82.

111. Mariani LL, Klein I, Pico F. Hypoplasia or stenosis: usefulness of high-resolution MRI. Rev Neurol (Paris). 2011;167:619-21.

112. Zhu X-J, Wang W, Du B, Liu L, He X-X, Hu L-B, et al. Wall imaging for unilateral intracranial vertebral artery hypoplasia with three-dimensional high-isotropic resolution magnetic resonance images. Chin Med J (Engl). 2015;128:1601-6.

113. Li M, Wu S-W, Xu W-H. High-resolution MRI of radiation-induced intracranial vasculopathy. Neurology. 2015;84:631.

\section{Submit your next manuscript to BioMed Central and we will help you at every step:}

- We accept pre-submission inquiries

- Our selector tool helps you to find the most relevant journal

- We provide round the clock customer support

- Convenient online submission

- Thorough peer review

- Inclusion in PubMed and all major indexing services

- Maximum visibility for your research

Submit your manuscript at www.biomedcentral.com/submit
( ) BioMed Central 